\title{
Efeitos da origem e da linhagem do DNA mitocondrial sobre características produtivas e reprodutivas de bovinos leiteiros da raça Gir
}

\author{
[Effects of origin and lineage of mitochondrial DNA on productive and \\ reproductive traits of Gir dairy cattle] \\ S.H.A. Ribeiro ${ }^{1}$, J.C.C. Pereira ${ }^{2}$, R.S. Verneque ${ }^{3,5}$, M.A. Silva ${ }^{2,5}$, \\ J.A.G. Bergmann ${ }^{2,5}$, I.L. Ledic ${ }^{3}$, O.R. Morais ${ }^{4}$ \\ ${ }^{1}$ EPAMIG - Uberaba, MG. \\ ${ }^{2}$ Escola de Veterinária - UFMG - Belo Horizonte, MG \\ ${ }^{3}$ Embrapa Gado de Leite - Juiz de Fora, MG \\ ${ }^{4}$ EPAMIG - Prudente de Moraes, MG \\ ${ }^{5}$ Bolsista do CNPq
}

\begin{abstract}
RESUMO
Avaliou-se a influência do DNA mitocondrial sobre características de produção e reprodução em rebanho Gir. Foram analisados, segundo a origem mitocondrial (indicus ou taurus) e linhagem citoplasmática (fêmeas fundadoras), 3385 registros de produção total de leite (PT), produção de leite até os 305 dias de lactação (P305) e de período de lactação (PL); 2394 registros de intervalo de parto (IP) e de produção de leite por dia de intervalo de partos (PIP) e 618 registros de idade ao primeiro parto (IPP). A origem mitocondrial foi incluída no modelo como efeito fixo para a idade ao primeiro parto, por ter, em análise prévia, demonstrado ser significativa somente para essa característica. A estimação dos componentes de variância e parâmetros genéticos bem como a predição dos valores genéticos foram realizadas a partir de dois modelos animais; com e sem a inclusão da variável aleatória, linhagem citoplasmática, com o programa MTDFREML, pelo método da máxima verossimilhança restrita com algoritmo livre de derivadas. A linhagem citoplasmática explicou $1,6 \% ; 1,5 \% ; 1,2 \%, 0 \%, 0 \%$ e $0 \%$, da variância fenotípica das características PT, P305, PL, IP, PIP e IPP, não obstante não se mostrou significativa no teste de razão de máxima verossimilhança. As correlações de postos entre os valores genéticos obtidos a partir dos modelos com e sem a inclusão da linhagem citoplasmática foram próximas à unidade para todas as características. O modelo que não incluiu a linhagem citoplasmática viesou apenas as tendências genéticas das características PT, P305 e PL. A origem mitocondrial, indicus ou taurus, somente foi significativa $(\mathrm{P}<0,05)$ para a variação da idade ao primeiro parto. A linhagem citoplasmática não contribuiu significativamente para a variância fenotípica de quaisquer das características deste estudo.
\end{abstract}

Palavras-chave: gado de leite, Gir, efeito citoplasmático, origem mitocondrial

\begin{abstract}
This study was carried out to evaluate the mitochondrial DNA effect on production and reproduction traits of Gir breed. A total of 3,385 records of milk production (MP), 305-day milk production (305-MP), and lactation length (LL); and 2,394 records of calving interval (CI), milk production per day of calving interval (MPPDCI), and age at first calving (AFC) were analyzed according to mitochondrial DNA origin (indicus or taurus) and cytoplasmatic lineages (foundation cows). The mitochondrial DNA origin was considered as fixed effect for age at first calving analysis. Genetic parameter estimates and predicted breeding values were obtained by restricted maximum likelihood derivative free algorithm using two different animal models (including or not cytoplasmatic lineage effect). Maximum likelihood ratio test showed a non significant effect of cytoplasmatic lineages on all analyzed traits. Cytoplasmatic lineages accounted not significantly for 1.6\%, 1.5\%, 1.2\%, 0\%, and $0 \%$ of the total phenotypic variance of MP,
\end{abstract}

Recebido em 30 de julho de 2008

Aceito em 11 de dezembro de 2008

E-mail: sandro.ribeiro@epamiguberaba.com.br 
305-MP, LL, MPPDCI and AFC. Ranks correlation among breeding values from both models were close to one for all analyzed traits. No mitochondrial lineage model biased upward only estimates of genetic trends of MP, 305-MP, and LL traits. Mitochondrial origin (taurus or indicus) significantly accounted $(P<0.05)$ only for total variation of age at first calving. Cytoplasmatic lineages did not account significantly for the phenotypic variation of any of the studied traits.

\section{Keywords: dairy cattle, Gir breed, cytoplasmatic effect, mitochondrial origin}

\section{INTRODUÇÃO}

O DNA mitocondrial é aproximadamente 17000 vezes menor que o nuclear e, apesar do pequeno tamanho, é responsável por codificar 13 proteínas (enzimas) essenciais para o processo de geração de energia para as atividades celulares (Gibson et al., 1997). Tem como peculiaridade a herança exclusivamente materna, não apresentando segregação mendeliana, o que lhe propicia ser foco de muitos estudos filogenéticos. Outras questões referentes à sua origem e à razão de possuir conjunto tão específico de genes vêm sendo respondidas na biologia. A teoria mais aceita é a de que se originaram no decorrer da evolução, a partir de uma relação endossimbiótica, promovida pela invasão de células ancestrais eucariontes por células procariontes, bactérias capazes de utilizarem o oxigênio, elemento abundante na atmosfera primitiva, para a geração de energia. Nesta relação, enquanto a célula eucarionte fornecia proteção e compostos orgânicos, a procarionte possibilitava maior ganho enérgico a partir destes. Conjectura-se que existiria maior conjunto gênico nas células procariontes ancestrais e que, com o passar dos anos, por já não terem funcionalidade explícita, ou perderamse ou migraram-se para o núcleo. Contudo, os genes cernes, responsáveis pelo estabelecimento da relação endossimbiótica, permaneceram. Atualmente, a maioria das células eucariontes é totalmente dependente dos genes organelares para seu funcionamento normal. (Griffiths et al., 2002)

Outros pontos de questionamentos envolvendo o DNA mitocondrial são a sua provável contribuição na variação das características de crescimento, produção e reprodução. Muitos estudos já foram realizados, obtendo resultados importantes dessa sobre características ligadas à produção e composição do leite, especificamente, na percentagem de gordura, na concentração de energia e na idade ao primeiro parto (Schutz et al., 1992, 1993; Boettcher et al.,
1996; Henkes et al., 2004). Contudo, todos os trabalhos sobre $\mathrm{o}$ tema da influência citoplasmática em características de produção e reprodução foram desenvolvidos nas raças da subespécie taurus, sendo ainda inédita qualquer tentativa de se identificar a influência citoplasmática para essas características na subespécie indicus. Este estudo teve como objetivo avaliar a influência da origem mitocondrial e da linhagem citoplasmática na variação fenotípica das características de produção e reprodução em rebanho Gir aptidão leiteira

\section{MATERIAL E MÉTODOS}

Os dados foram extraídos dos registros zootécnicos pertencentes à Fazenda Experimental Getúlio Vargas (FEGT) da EPAMIG, obtidos entre os anos de 1953 a 2002. A fazenda, localizada no município de Uberaba, MG, possui um dos mais tradicionais rebanhos Gir leiteiro do país. Fundada em 1948, quando foram adquiridas 30 matrizes de fazendas particulares da região, algumas das vacas Gir já existentes na propriedade participaram da formação inicial do rebanho. Nos anos 1952 e 1962, foram adquiridos de diversos criadores novos grupos de 96 e 15 vacas, respectivamente. Após essa última aquisição de animais, houve pouco ingresso de fêmeas no rebanho (Ledic et al., 2004), formando, deste modo, um rebanho com várias origens e com possível múltiplo tipos de linhagens citoplasmáticas (fêmeas fundadoras do rebanho), cada uma com várias gerações de descendentes.

As linhagens citoplasmáticas, consideradas como sendo as fêmeas fundadoras do rebanho, foram identificadas pelo programa LINMAT, descrito em Mourão et al. (2006), traçando caminhos das fêmeas atuais até as primeiras fêmeas ancestrais no pedigree. Depois de identificadas as linhagens, amostras de sangue de dois a três representantes de cada foram analisadas segundo a metodologia descrita em Meirelles et al. 
(1999), a qual permite, pela observação de polimorfismos no DNA mitocondrial, separar as linhagens em dois grandes grupos: indicus ou taurus. Entretanto, em prévia análise de variância, somente se observou efeito significativo da variável origem mitocondrial (indicus ou taurus) na idade ao primeiro parto, a qual juntamente com o ano e a época de nascimento foram relacionados como efeitos fixos para esta característica. Para todas as outras características, considerou-se o ano e a época de parto, e, como covariável de efeito linear e quadrático, a idade da vaca por ocasião do parto. As épocas de parto e de nascimento foram discriminadas como 1, quando compreendidas entre os meses de abril a setembro, e como 2, quando compreendidas entre os meses de outubro a março do ano subsequente, em razão das diferenças entre as condições climáticas e de disponibilidade de forrageiras.

Utilizaram-se, na consistência dos dados e na formação dos arquivos para análise, os procedimentos do programa SAS/1995. Neste processo, foram excluídos: os registros de lactações com encerramento, comprovadamente anormal, ou seja, que foram encerradas ou que se encerraram em virtude de outros fatores que não

$$
\mathrm{Y}_{\mathrm{IJK}}=\mathrm{AEP}_{\mathrm{I}}+\beta_{1}\left(\mathrm{I}_{\mathrm{IJK}}-\mathrm{I}\right)+\beta_{2}\left(\mathrm{I}_{\mathrm{IJK}}-\mathrm{I}\right)^{2}+\mathrm{A}_{\mathrm{IJ}}+\mathrm{EP}_{\mathrm{IJ}}+\mathrm{C}_{\mathrm{IJ}}+\mathrm{e}_{\mathrm{IJK}} \text { emque }
$$

$\mathrm{Y}_{\mathrm{ijk}}=$ qualquer das características, exceto a idade ao primeiro parto, da vaca $\mathrm{j}$, no ano e na época de parto $\mathrm{i}, \mathrm{AEP}_{\mathrm{i}}=$ efeito fixo do $\mathrm{i}^{\text {inésimo }}$ ano e época de parto, $\beta_{1}$ e $\beta_{2}=$ coeficientes de regressão linear e quadrático da idade da vaca $\mathrm{Y}_{\mathrm{IJK}}$ com relação à idade ao parto, $\mathrm{A}_{\mathrm{ij}}=$ efeito genético aditivo direto do animal $\mathrm{j}$, tomado como aleatório no ano e na época $\mathrm{i}, \mathrm{EP}_{\mathrm{ij}}=$ efeito de ambiente permanente do animal $\mathrm{j}$, tomado como a baixa produção; os intervalos de partos maiores que 728 dias; reprodutores com menos de três filhos; anos e épocas de parto que apresentaram menos de três registros de produção e linhagens citoplasmáticas com menos de cinco representantes com registros próprios de produção. Ao final do processo, foram gerados dois arquivos, um genealógico, com matriz de parentesco constituída por 1649 animais, e outro zootécnico, com 1017 animais, 2394 intervalos de partos, totalizando 3385 lactações, com média de 3,3 lactações por vaca.

$\mathrm{Na}$ obtenção dos parâmetros estatísticos descritivos e das estimativas dos componentes de covariância para os efeitos genéticos, fenotípicos e de ambiente, foi utilizado o programa MTDFREML sob dois tipos de modelos, que se distinguiam pela inclusão ou não da variável linhagem citoplasmática, a qual foi considerada aleatória e não correlacionada ao efeito aditivo direto.

Os modelos mistos completos utilizados foram;

a) Todas as características, com exceção da idade ao primeiro parto,

$$
\mathrm{Y}_{\mathrm{IJKL}}=\mathrm{AEN}_{\mathrm{I}}+\mathrm{OM}_{\mathrm{J}}+\mathrm{A}_{\mathrm{IJk}}+\mathrm{C}_{\mathrm{IJk}}+\mathrm{e}_{\mathrm{IJKL}} \text {, em que }
$$

$Y_{i j k}=$ idade ao primeiro parto, da vaca $j$, no ano e na época $i, A_{E N}=$ efeito fixo do i inésimo ano e época de nascimento, $\mathrm{OM}_{\mathrm{j}}=$ efeito fixo da $\mathrm{j}^{\text {nésima }}$ origem mitocondrial, $\mathrm{A}_{\mathrm{ij}}=$ efeito genético aditivo direto do animal $\mathrm{j}$, tomado como aleatório aleatório independente de $\mathrm{A}_{\mathrm{ij}}$, no ano e na época $\mathrm{i}, \mathrm{C}_{\mathrm{ij}}=$ efeito da linhagem citoplasmática do animal $\mathrm{j}$, tomado como aleatório independente de $A_{i j}$, no ano e na época $i, e_{i j k}=$ erro aleatório associado a cada observação, suposto normal e independente,

b) para a idade ao primeiro parto, no ano e na época $\mathrm{i}, \mathrm{C}_{\mathrm{ij}}=$ Efeito da linhagem citoplasmática do animal $\mathrm{j}$, tomado como aleatório independente de $\mathrm{A}_{\mathrm{ij}}$, no ano e na época $\mathrm{i}, \mathrm{e}_{\mathrm{ijk}}=$ erro aleatório associado a cada observação, suposto normal e independente. 


\section{RESULTADOS E DISCUSSÃO}

De um total de 1017 animais, 803 animais tiveram seus DNA mitocondriais identificados, sendo que $646(80,4 \%)$ apresentaram DNA mitocondrial de taurinos e $157(19,6 \%)$ de indicus (Tab. 1). Este fato confirma o observado por Meirelles et al. (1999) de que a maioria do Zebu nacional, mais explicitamente o Gir e o Nelore, advém de cruzamentos de touros Bos taurus indicus com vacas Bos taurus taurus, originárias da Península Ibérica. Segundo os mesmos autores, esse fato coloca o Zebu em condição ímpar para o estudo da influência da herança mitocondrial sobre características de produção, pois ter-se-iam animais distintos quanto ao DNA mitocondrial, mas similares quanto ao nuclear. Contudo, neste estudo, somente houve influência significativa $(\mathrm{P}<0,05)$ da origem mitocondrial (indicus ou taurus) na idade ao primeiro parto, sendo os animais taurinos, em média, 30,1 dias mais precoces que os de origem indiana.

Tabela 1. Linhagens citoplasmáticas, origem mitocondrial, número de representantes e contribuição para o efetivo populacional do rebanho

\begin{tabular}{cccccccc}
\hline $\begin{array}{c}\text { Linhagem } \\
\text { materna }\end{array}$ & DNAmit & $\mathrm{N}$ & $\%$ & $\begin{array}{c}\text { Linhagem } \\
\text { materna }\end{array}$ & DNAmit & $\mathrm{N}$ & $\%$ \\
\hline 10041 & indicus & 17 & 1,67 & 10056 & $*$ & 14 & 1,38 \\
10050 & indicus & 65 & 6,39 & 10057 & $*$ & 17 & 1,67 \\
10054 & indicus & 53 & 5,21 & 10058 & $*$ & 6 & 0,59 \\
10089 & indicus & 22 & 2,16 & 10061 & $*$ & 18 & 1,77 \\
10001 & $*$ & 7 & 0,69 & 10062 & taurus & 13 & 1,28 \\
10003 & taurus & 20 & 1,97 & 10064 & taurus & 33 & 3,24 \\
10007 & $*$ & 5 & 0,49 & 10068 & taurus & 44 & 4,33 \\
10008 & taurus & 65 & 6,39 & 10069 & $*$ & 24 & 2,36 \\
10010 & taurus & 42 & 4,13 & 10071 & $*$ & 7 & 0,69 \\
10017 & taurus & 76 & 7,47 & 10072 & $*$ & 6 & 0,59 \\
10019 & $*$ & 8 & 0,79 & 10074 & $*$ & 5 & 0,49 \\
10027 & taurus & 39 & 3,83 & 10075 & $*$ & 6 & 0,59 \\
10031 & $*$ & 6 & 0,59 & 10079 & taurus & 32 & 3,15 \\
10034 & $*$ & 15 & 1,47 & 10080 & $*$ & 14 & 1,38 \\
10035 & taurus & 63 & 6,19 & 10082 & taurus & 61 & 6,00 \\
10036 & taurus & 21 & 2,06 & 10083 & taurus & 5 & 0,49 \\
10039 & $*$ & 5 & 0,49 & 10098 & $*$ & 13 & 1,28 \\
10042 & taurus & 12 & 1,18 & 10100 & $*$ & 11 & 1,08 \\
10044 & taurus & 27 & 2,65 & 10101 & $*$ & 7 & 0,69 \\
10047 & taurus & 29 & 2,85 & 10102 & $*$ & 5 & 0,49 \\
10052 & $*$ & 5 & 0,49 & 10108 & taurus & 8 & 0,79 \\
10053 & $*$ & 10 & 0,98 & 10109 & taurus & 12 & 1,18 \\
10055 & taurus & 44 & 4,33 & & & & \\
\hline
\end{tabular}

$\mathrm{LC}=$ linhagem citoplasmática; $\mathrm{N}=$ número de representantes.

Os componentes de variância obtidos por análise unicaracterística são apresentados na Tab. 2

A linhagem citoplasmática exerceu pouca influência sobre as estimativas dos componentes de variância das características de produção total, produção até os 305 dias de lactação e período de lactação, sendo mais notório na primeira, enquanto nas características, intervalo de partos, produção por dia de intervalo de partos e idade ao primeiro parto, sua influência foi nula. Apesar de a contribuição da linhagem citoplasmática ser pequena, quando comparada com a dos outros componentes de variância, sua inclusão nos modelos de análise promoveu alterações na estimação dos demais componentes. As principais alterações observadas foram a redução no componente de variância aditiva direta e um discreto aumento no componente de variância de meio permanente.

Os parâmetros genéticos obtidos com e sem a inclusão da linhagem citoplasmática são apresentados na Tab. 3 
Tabela 2. Componentes de variância obtidos por análise unicaracterística com os modelos 1 e 2

\begin{tabular}{|c|c|c|c|c|c|c|}
\hline \multirow[b]{2}{*}{ Característica } & \multirow{2}{*}{$\frac{\frac{0}{0}}{\frac{0}{0}}$} & \multicolumn{5}{|c|}{ Componentes de variância } \\
\hline & & $\sigma_{\mathrm{p}}^{2}$ & $\sigma_{\mathrm{a}}^{2}$ & $\sigma_{\mathrm{pe}}^{2}$ & $\sigma_{\mathrm{lc}}^{2}$ & $\sigma_{\mathrm{e}}^{2}$ \\
\hline \multirow{2}{*}{ PT (kg) } & 1 & 607244,42 & 158613,63 & 135960,00 & 9887,71 & 302782,70 \\
\hline & 2 & 607651,14 & 171805,84 & 133076,00 & - & 302769,33 \\
\hline \multirow{2}{*}{ P305 (kg) } & 1 & 501434,80 & 137469,47 & 107884,00 & 7716,11 & 248365,09 \\
\hline & 2 & 501441,25 & 146960,96 & 106182,00 & - & 248298,63 \\
\hline \multirow{2}{*}{ PL (dias) } & 1 & 4683,36 & 876,29 & 922,64 & 55,13 & 2829,29 \\
\hline & 2 & 4688,16 & 953,23 & 906,05 & - & 2828,88 \\
\hline \multirow{2}{*}{ IP (dias) } & 1 & 7203,66 & 398,82 & 842,15 & 0,02 & 5962,69 \\
\hline & 2 & 7203,24 & 399,50 & 842,41 & - & 5961,32 \\
\hline \multirow{2}{*}{ PIP (kg) } & 1 & 2,69 & 0,65 & 0,29 & 0,00 & 1,76 \\
\hline & 2 & 2,70 & 0,65 & 0,28 & - & 1,76 \\
\hline \multirow{2}{*}{ IPP (meses) } & 1 & 47,20 & 13,84 & - & 0,00 & 33,36 \\
\hline & 2 & 47,19 & 13,83 & - & - & 33,37 \\
\hline
\end{tabular}

$\sigma_{\mathrm{P}}^{2}=$ variância fenotípica; $\sigma_{\mathrm{a}}^{2}=$ variância genética aditiva direta; $\sigma_{\mathrm{pe}}^{2}=$ variância de ambiente permanente; $\sigma_{\mathrm{lc}}^{2}=$ variância da linhagem citoplasmática; $\sigma_{\mathrm{e}}^{2}=$ variância residual. $\mathrm{PT}=$ produção total de leite; $\mathrm{P} 305=$ produção de leite até os 305 dias de lactação; $\mathrm{PL}=$ período de lactação; $\mathrm{IP}=$ intervalo de partos; $\mathrm{PIP}=$ produção de leite por dia de intervalo de partos; IPP $=$ idade ao primeiro parto. Modelo $1=$ todas as características exceto a idade ao primeiro parto; Modelo 2= idade ao primeiro parto.

Tabela 3. Parâmetros genéticos das características obtidos por análises unicaracterística com os modelos 1 e 2

\begin{tabular}{lccccc}
\hline \multirow{2}{*}{ Característica } & Modelo & \multicolumn{4}{c}{ Parâmetro genético } \\
\cline { 3 - 5 } & & $\mathrm{h}_{\mathrm{a}}^{2}$ & $\mathrm{c}^{2}$ & $\mathrm{lc}^{2}$ & $\mathrm{e}^{2}$ \\
\hline \multirow{2}{*}{ PT (kg) } & 1 & 0,26 & 0,22 & 0,016 & 0,50 \\
& 2 & 0,28 & 0,22 & - & 0,50 \\
P305 (kg) & 1 & 0,27 & 0,22 & 0,015 & 0,50 \\
& 2 & 0,29 & 0,21 & - & 0,50 \\
PL (dias) & 1 & 0,19 & 0,20 & 0,012 & 0,60 \\
& 2 & 0,20 & 0,19 & - & 0,60 \\
IP (dias) & 1 & 0,06 & 0,12 & 0,000 & 0,83 \\
& 2 & 0,06 & 0,12 & - & 0,83 \\
PIP (kg) & 1 & 0,24 & 0,11 & 0,002 & 0,65 \\
& 2 & 0,24 & 0,11 & - & 0,65 \\
IPP (meses) & 1 & 0,29 & - & 0,000 & 0,71 \\
& 2 & 0,29 & - & - & 0,71 \\
\hline
\end{tabular}

$\mathrm{h}_{\mathrm{a}}^{2}=$ herdabilidade direta; $\mathrm{c}^{2}=$ fração de meio permanente; $\mathrm{lc}^{2}=$ fração da linhagem citoplasmática; $\mathrm{e}^{2}=$ fração do resíduo. $\mathrm{PT}=$ produção total de leite; $\mathrm{P} 305=$ produção de leite até os 305 dias de lactação; $\mathrm{PL}=$ período de lactação; $\mathrm{IP}=$ intervalo de partos; $\mathrm{PIP}=$ produção de leite por dia de intervalo de partos; $\mathrm{IPP}=$ idade ao primeiro parto. Modelo $1=$ todas as características exceto a idade ao primeiro parto; Modelo $2=$ idade ao primeiro parto.

Observa-se na Tab. 3 que a contribuição da linhagem citoplasmática correspondeu, respectivamente, a $1,6 \% ; 1,5 \%$ e $1,2 \%$ da variância fenotípica das características produção total de leite, produção de leite até 305 dias de lactação e período de lactação, o que não foi significativo no teste de razão de máxima verossimilhança apresentado na Tab. 4. 
Tabela 4. Teste da razão de máxima verossimilhança entre os modelos que inclúam (modelo 1) ou não (modelo 2) a variável de linhagem citoplasmática

\begin{tabular}{lrrrr}
\multicolumn{1}{c}{ Característica } & Modelo 1 & Modelo 2 & $\begin{array}{c}\text { Razão de } \\
\text { verossimilhança }\end{array}$ & Significância \\
\hline PT & 46264,78696 & 46268,22369 & $-3,44$ & ns \\
P305 & 45617,96552 & 45621,03234 & $-3,07$ & ns \\
PL & 30688,17094 & 30690,56032 & $-2,39$ & ns \\
IP & 22875,45121 & 22875,45120 & 0,00 & ns \\
PIP & 4501,28954 & 4501,31901 & $-0,03$ & ns \\
IPP & 2796,63222 & 2796,63222 & 0,00 & ns \\
\hline Ad
\end{tabular}

Adaptado de Oliveira (2005).

Teste de $\chi_{1 ; 0,05}^{2}=3,84$; razão de verossimilhança $<3,84=$ não significativo (ns)

$\mathrm{PT}=$ produção total de leite; $\mathrm{P} 305=$ produção de leite até os 305 dias de lactação; $\mathrm{PL}=$ período de lactação; $\mathrm{IP}=$ intervalo de partos; $\mathrm{PIP}=$ produção por dia de intervalo de partos; IPP= idade ao primeiro parto. Modelo $1=$ todas as características exceto a idade ao primeiro parto; Modelo 2= idade ao primeiro parto.

Resultados semelhantes a estes foram relatados por Boettcher et al. (1996); Rorato et al. (1999) e Albuquerque et al. (1998), que observaram a linhagem citoplasmática contribuindo com $0,38 \%$ a $1,6 \%$ da variância fenotípica da produção de leite. Esses autores também a notificaram como não significativa. Quanto à contribuição para a variância fenotípica do intervalo de partos e da idade ao primeiro parto, somente a da primeira característica aproximouse a deste estudo. Henkes et al. (2004) observaram contribuição de $15 \%$ da linhagem citoplasmática na variância fenotípica da idade ao primeiro parto em bovinos mestiços (3/8 Nelore x 5/8 Aberdeen Angus). Estimativas da contribuição da linhagem citoplasmática para período de lactação não foram encontradas na literatura.

Embora a linhagem citoplasmática não tenha apresentado contribuição significativa $(\mathrm{P}<0,05)$, as alterações ocasionadas pela sua inclusão ao modelo promoveram, pela redução do componente aditivo direto, herdabilidades diretas mais baixas para as características de produção total de leite, produção de leite até 305 dias de lactação e período de lactação. Boettcher et al. (1996) e Pelicioni e Queiróz (2001) já haviam mencionado a ocorrência dessas alterações nos componentes de variância e a importância de se incluir a linhagem citoplasmática nos modelos de avaliação para melhor partição da variância fenotípica. Pelicioni e Queiróz (2001) concluíram, ao observarem as mesmas alterações aqui identificadas, que, apesar de a linhagem citoplasmática não apresentar efeito significativo à sua inclusão nos modelos de avaliação, poderia ser justificada por proporcionar melhor ajuste nos dados, explicando melhor a variância e propiciando estimativas mais fidedignas dos parâmetros genéticos.

A fim de avaliar se as alterações promovidas nos parâmetros genéticos pela inclusão da linhagem citoplasmática influenciavam a ordenação final dos animais com consequente alteração na seleção e no ganho genético, foram realizados cálculos de correlação de posto de Spearman entre os dois conjuntos de valores genéticos preditos pelos modelos 1 e 2 e traçadas as tendências genéticas obtidas com os dois modelos. Os valores das correlações são apresentados na Tab. 5, e as tendências na Tab. 6 e nas Fig. de 1 a 6.

A correlação de posto de Spearman entre os valores genéticos dos dois modelos foi muito próxima à unidade, mostrando que, apesar das diferenças entre os dois conjuntos de valores genéticos, houve poucas modificações na ordenação e, consequentemente, na seleção dos animais quanto ao seu mérito genético.

Tendências genéticas e fenotípicas de cada característica foram estimadas pela regressão das médias dos valores genéticos e fenotípicos sobre ano de nascimento. As estimativas dos ganhos genéticos e fenotípicos, com seus respectivos erros-padrão, estão listadas na Tab. 6.

Nas figuras 1 a 6, são apresentadas as tendências genéticas e fenotípicas das características estudadas. 


\section{Ribeiro et al.}

Tabela 5. Valores da correlação de Spearman entre os valores genéticos preditos sob os modelos que incluíam (modelo 1) ou não (modelo 2) a variável linhagem citoplasmática

\begin{tabular}{|c|c|c|c|c|c|c|c|}
\hline \multirow{2}{*}{\multicolumn{2}{|c|}{$\begin{array}{l}\text { Coeficiente de } \\
\text { correlação de } \\
\text { Spearman }\end{array}$}} & \multicolumn{6}{|c|}{ Modelo 1} \\
\hline & & PT & P305 & PL & IP & PIP & IPP \\
\hline \multirow{6}{*}{$\begin{array}{l}\frac{N}{0} \\
\frac{0}{0} \\
\frac{0}{2}\end{array}$} & $\mathrm{PT}$ & 0,98968 & $*$ & $*$ & $*$ & $*$ & $*$ \\
\hline & P305 & $*$ & 0,99140 & $*$ & $*$ & $*$ & $*$ \\
\hline & PL & $*$ & $*$ & 0,99080 & $*$ & $*$ & $*$ \\
\hline & IP & $*$ & $*$ & $*$ & 1,000 & $*$ & $*$ \\
\hline & PIP & $*$ & $*$ & $*$ & $*$ & 0,99976 & $*$ \\
\hline & IPP & $*$ & $*$ & $*$ & $*$ & $*$ & 1,000 \\
\hline
\end{tabular}

$\overline{\mathrm{PT}}=$ produção total de leite; $\mathrm{P} 305=$ produção de leite até os 305 dias de lactação; $\mathrm{PL}=$ período de lactação; $\mathrm{IP}=$ intervalo de partos; $\mathrm{PIP}=$ produção por dia de intervalo de partos; IPP= idade ao primeiro parto. Modelo $1=$ todas as características exceto a idade ao primeiro parto; Modelo $2=$ idade ao primeiro parto.

Tabela 6. Estimativas das tendências genéticas (modelos 1 e 2) e fenotípicas no período de 1953 a 2002

\begin{tabular}{|c|c|c|c|c|c|c|c|c|c|}
\hline \multirow{2}{*}{ Característica } & \multicolumn{6}{|c|}{ Tendência genética $\pm \mathrm{EP}$} & \multirow{2}{*}{$\begin{array}{l}\text { Tendências } \\
\text { fenotípicas }\end{array}$} & \multirow[b]{2}{*}{ \pm} & \multirow{2}{*}{ EP } \\
\hline & \multicolumn{3}{|c|}{ Modelo 1} & \multicolumn{3}{|c|}{ Modelo 2} & & & \\
\hline PT (kg) & $6,027 * * *$ & + & 0,673 & $6,360 * * *$ & + & 0,717 & $12,52 * * *$ & + & 2,52 \\
\hline P305 (kg) & $5,657 * * *$ & & 0,649 & $5,922 * * *$ & & 0,678 & $10,21 * * *$ & 1 & 2,41 \\
\hline PL (dias) & $0,413 * * *$ & 土 & 0,060 & $0,438 * * *$ & + & 0,060 & $-0,28^{\mathrm{ns}}$ & $\begin{array}{l} \pm \\
+\end{array}$ & 0,15 \\
\hline IP (dias) & $-0,014^{\mathrm{ns}}$ & & 0,028 & $-0,014^{\mathrm{ns}}$ & & 0,028 & $-0,92 * *$ & $\frac{1}{+}$ & 0,22 \\
\hline PIP $(\mathrm{kg})$ & $0,007 * * *$ & + & 0,001 & $0,007 * * *$ & & 0,001 & $0,04 * * *$ & $\frac{I}{+}$ & 0,007 \\
\hline IPP (meses) & $-0,0003^{\mathrm{ns}}$ & + & 0,011 & $-0,0003^{\mathrm{ns}}$ & + & 0,011 & $-0,11^{\mathrm{ns}}$ & $\frac{ \pm}{+}$ & 0,06 \\
\hline
\end{tabular}

$*(\mathrm{P}<0,05) ; * *(\mathrm{P}<0,001) ; * * *(\mathrm{P}<0, \overline{0} 001) ; \mathrm{ns}=$ não significativo.

$\mathrm{PT}=$ produção total de leite; $\mathrm{P} 305=$ produção até os 305 dias de lactação; $\mathrm{PL}=$ período de lactação; $\mathrm{IP}=$ intervalo de partos; $\mathrm{PIP}=$ produção de leite por dia de intervalo de partos; IPP= idade ao primeiro parto. Modelo $1=$ todas as características exceto a idade ao primeiro parto; Modelo 2= idade ao primeiro parto.
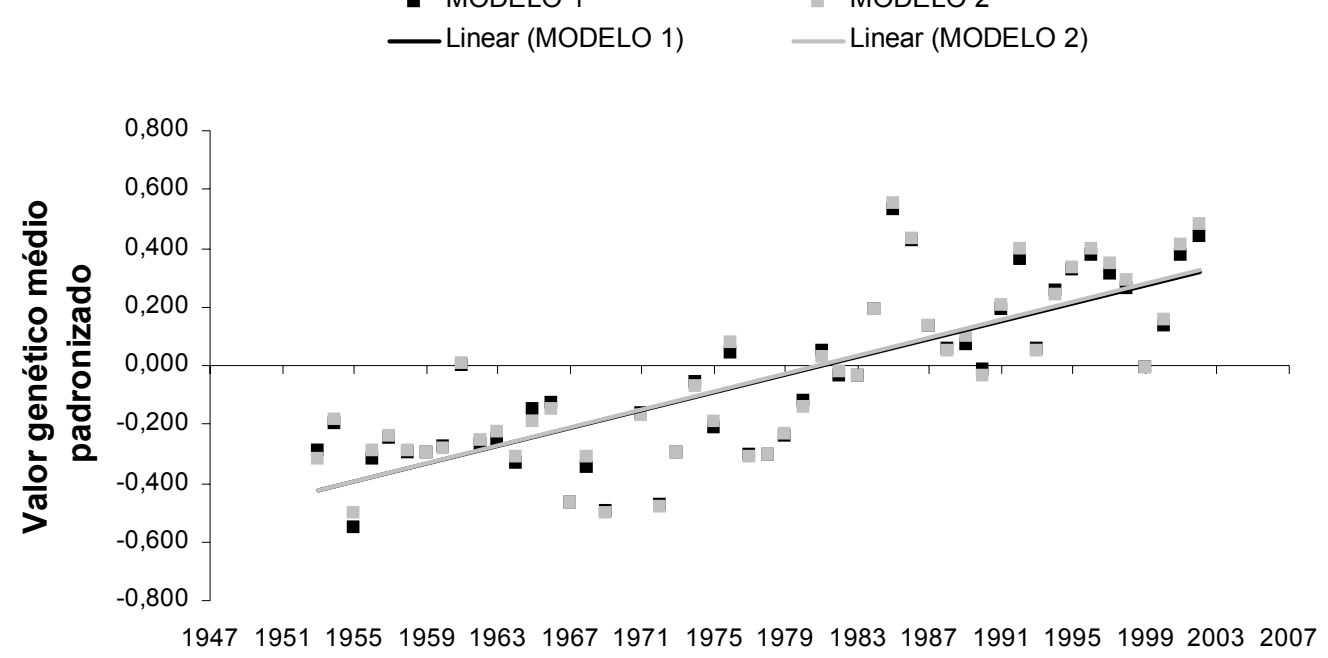

\section{Ano de nascimento}

Figura 1. Tendências genéticas, preditas por cada modelo e ponderadas pelo respectivo desvio-padrão genético, e fenotípicas da característica produção total de leite segundo o ano de nascimento da vaca, no período de 1952 a 2002. 
- MODELO 1

MODELO 2

- Linear (MODELO 1)

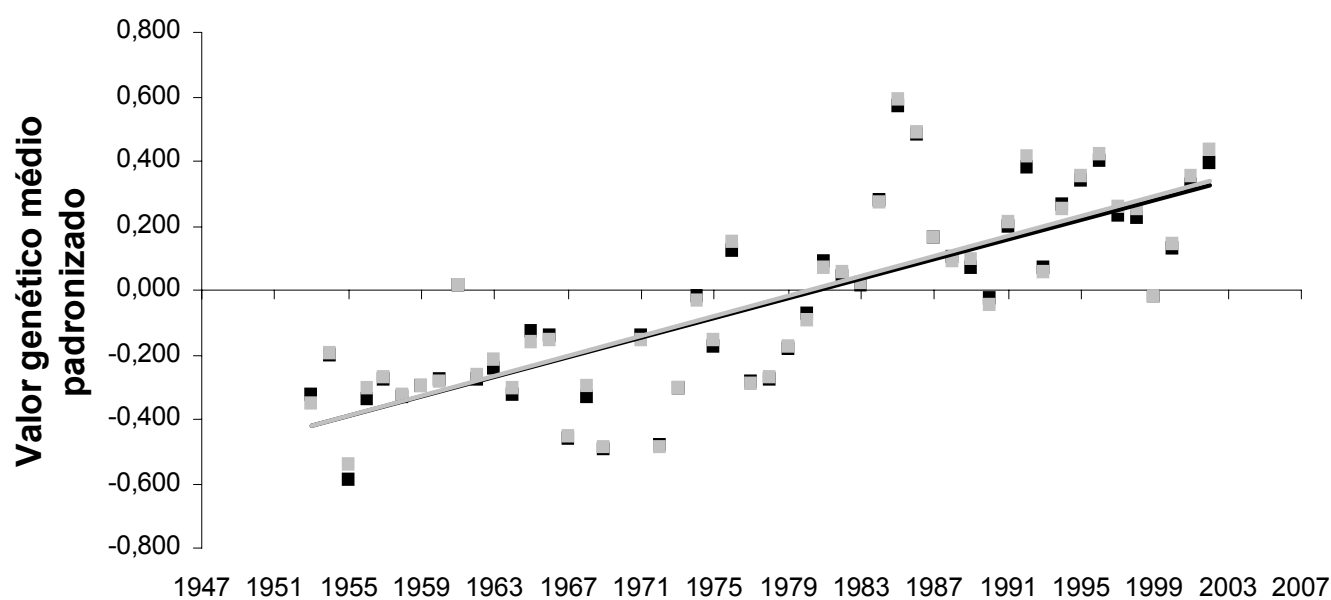

\section{Ano de nascimento}

Figura 2. Tendências genéticas, preditas por cada modelo e ponderadas pelo respectivo desvio-padrão genético, da característica produção de leite até os 305 dias de lactação, segundo o ano de nascimento da vaca, no período de 1952 a 2002.

- MODELO 1 MODELO 2

_ Linear (MODELO 1) _ Linear (MODELO 2)

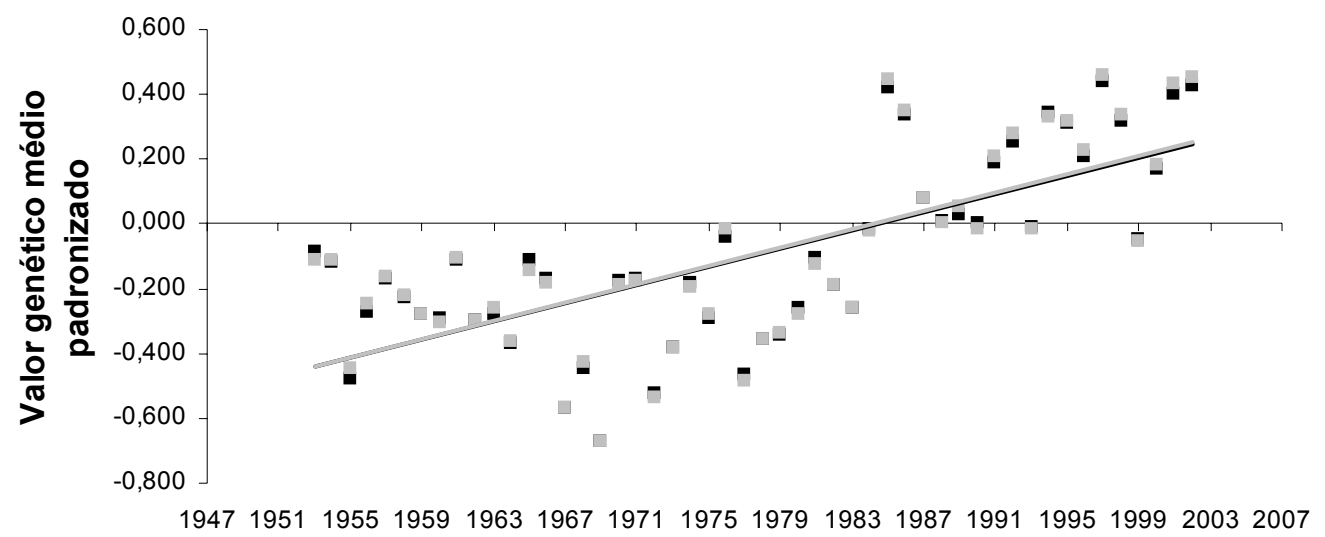

Ano de nascimento

Figura 3. Tendências genéticas, preditas por cada modelo e ponderadas pelo respectivo desvio-padrão genético, da característica período de lactação, segundo o ano de nascimento da vaca no período de 1952 a 2002 . 

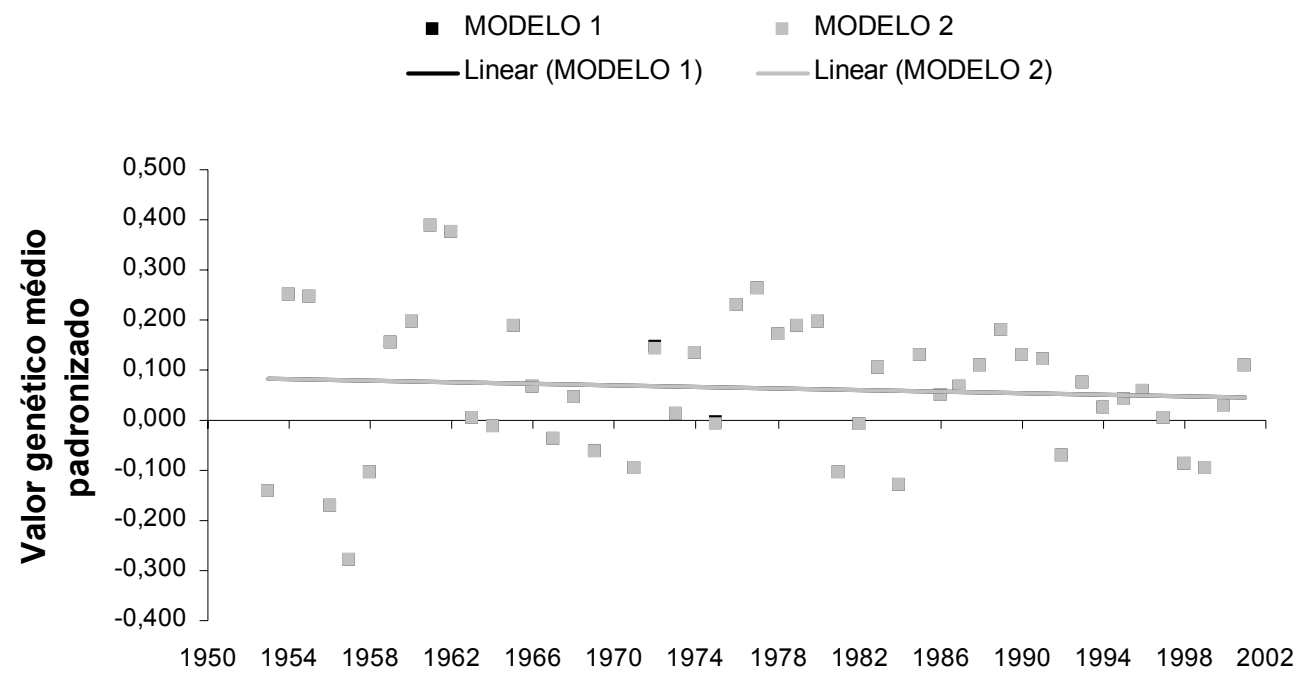

\section{Ano de nascimento}

Figura 4. Tendências genéticas, preditas por cada modelo e ponderadas pelo respectivo desvio-padrão genético, da característica intervalo de partos, segundo o ano de nascimento da vaca, no período de 1952 a 2002.

- MODELO 1 MODELO 2

_ Linear (MODELO 1) _ Linear (MODELO 2)

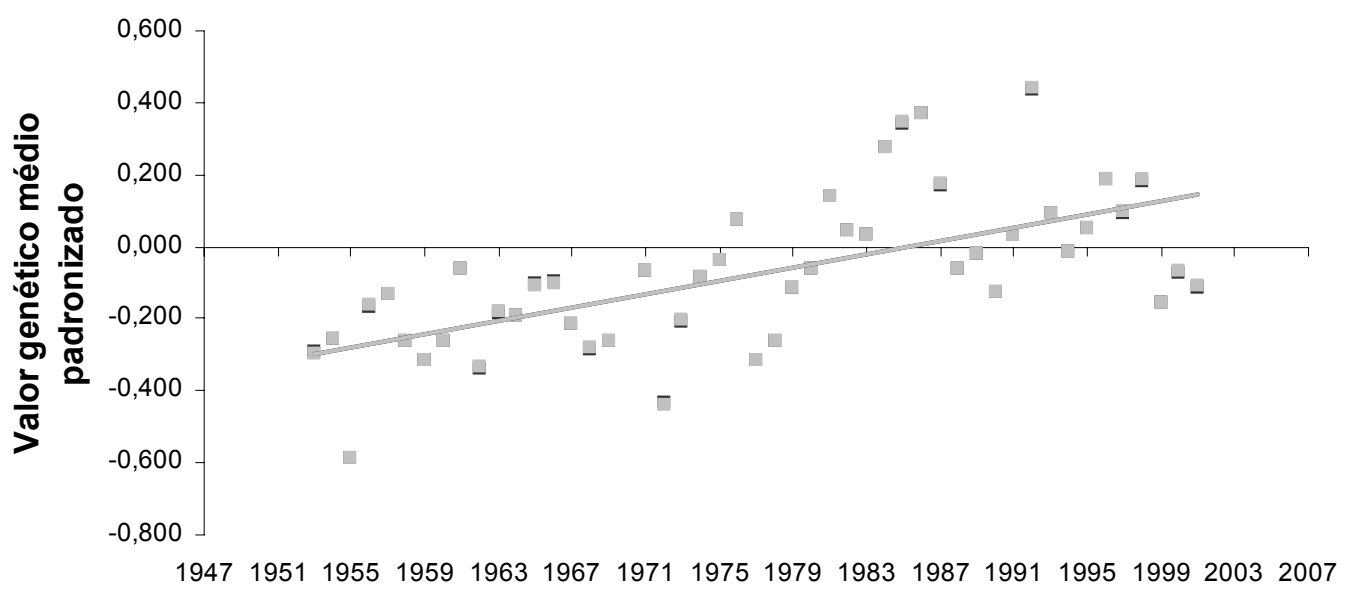

Ano de nascimento

Figura 5. Tendências genéticas, preditas por cada modelo e ponderadas pelo respectivo desvio-padrão genético, da característica produção de leite por dia de intervalo de partos, segundo o ano de nascimento da vaca, no período de 1952 a 2002. 


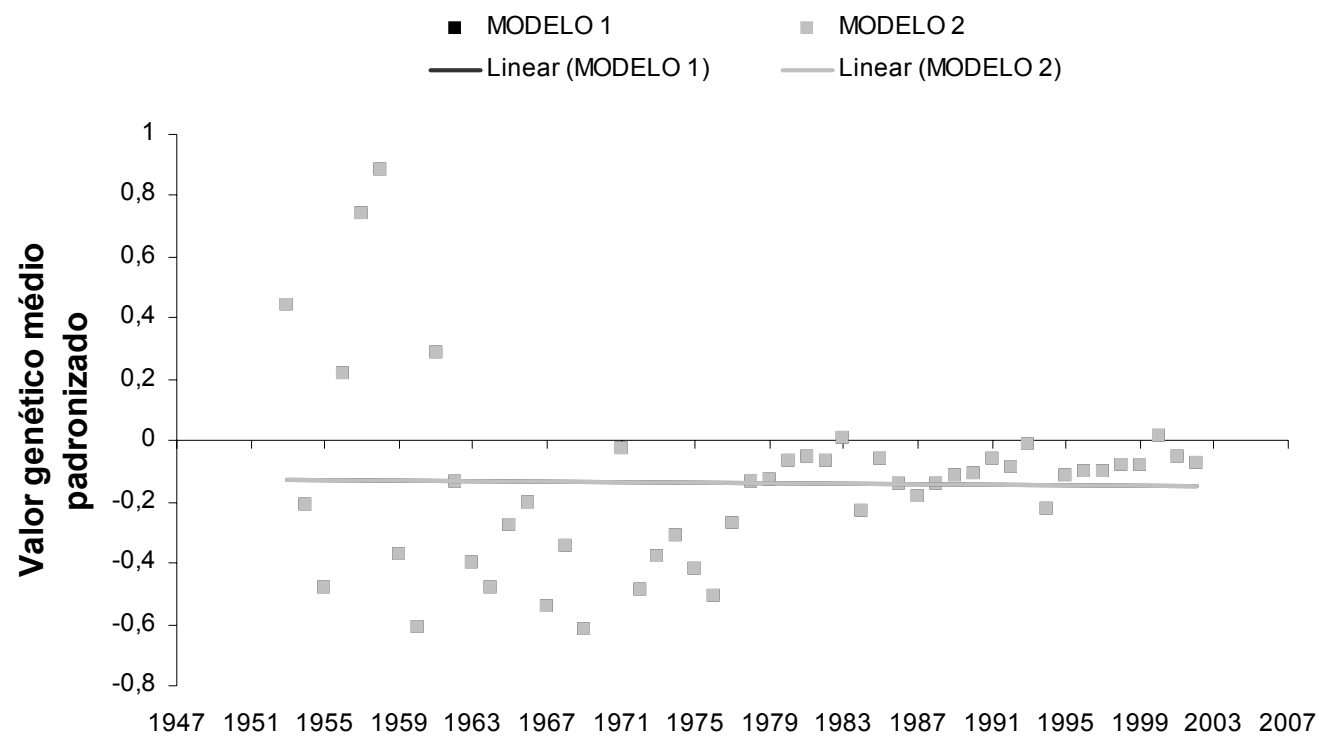

Ano de nascimento

Figura 6. Tendências genéticas, preditas por cada modelo e ponderadas pelo respectivo desvio-padrão genético da característica idade ao primeiro parto, segundo o ano de nascimento da vaca, no período de 1952 a 2002.

Com intuito de comparação, os valores genéticos obtidos pelos dois modelos foram ponderados pelo respectivo desvio-padrão genético antes de se traçarem as tendências. Observa-se que houve muito poucos vieses entre as tendências obtidas pelos dois modelos. Entre as características que apresentaram maior viés, estão a produção total de leite e o período de lactação, enquanto este não foi observado nas relacionadas à eficiência reprodutiva. Pode-se conjecturar que, embora os desvios tenham sido desprezíveis nesta escala de ganho, com o aumento nos ganhos, estes se tornariam maiores, entretanto neste estudo não foi identificado desvios importantes entre as tendências genéticas.

\section{CONCLUSÕES}

A origem mitocondrial, indicus ou taurus, considerada como efeito fixo no modelo de análise, foi estatisticamente significativa $(\mathrm{P}<0,05)$ apenas para a variação da idade ao primeiro parto, sendo, portanto, necessária na formação dos grupos de contemporâneo para essa característica. Os animais com DNA mitocondrial taurus tiveram o primeiro parto, em média, 31 dias mais precocemente que os com DNA mitocondrial indicus. O efeito atribuído à linhagem citoplasmática, identificado como as fêmeas fundadoras do rebanho e considerado como aleatório não correlacionado ao efeito genético aditivo direto, não contribuiu significativamente $(\mathrm{P}>0,05)$ para a variância fenotípica de quaisquer das características consideradas nesse estudo e, embora tenham existido pequenas alterações nas estimativas dos parâmetros genéticos, estas não resultaram em modificações significativas nas ordenações dos animais quanto ao mérito genético e nas tendências genéticas, não sendo, portanto, necessária a sua inclusão nos modelos de avaliação.

\section{REFERÊNCIAS BIBLIOGRÁFICAS}

ALBUQUERQUE, L.G.; KEOWN, J.F.; VAN VLECK, L.D. Variances of direct genetic effects, maternal genetics effects, and citoplasmic inheritance effects for milk yield, fat yield, and fat percentage. J. Dairy Sci., v.81, p.544-549, 1998.

BOETTCHER, P.J., KUHN, M.T., FREEMAN, A.E. Impacts of cytoplasmic inheritance on genetic evaluations. J. Dairy Sci., v.79, p.663675, 1996. 
GIBSON, J.P.; FREEMAN, A.E.; BOETTCHER, P.J. Cytoplasmic and mitochondrial inheritance of economic traits in cattle. Liv. Prod. Sci., v.47, p.115-124, 1997.

GRIFFITHS, A.J.F.; MILLER, J.H.; SUZUKI, D.T. et al. Genes extranucleares. In: Introdução à genética. 7.ed. Rio de Janeiro: Guanabara Koogan, 2002. p.583-604.

HENKES, L.E.; BENAVIDES, M.V.; OLIVEIRA, J.F.C. et. al. Maternal inheritance on reproductive traits in Brangus-Ibagé cattle. Cienc. Rural, v.34, p.1163-1167, 2004.

LEDIC, I.L.; FERNANDES, L.O.; VERNEQUE, R.S. et al. $O$ Gir leiteiro da Fazenda Experimental Getúlio Vargas. Belo Horizonte: EPAMIG, 2004. 28p. (Série Documentos, 40).

MEIRELLES, F.V.; ROSA, A.J.M.; LÔBO, R.B. et al. Is the american zebu really Bos indicus? Genet. Mol. Biol., v.22, p.543-546, 1999.

MOURÃO, G.B.; FIGUEIREDO, E.C.; MATOS, E.C. et. al. LINMAT - A maternal and citoplasmic line identification software. In:
WORLD CONGRESS ON GENETICS APPLIED TO LIVESTOCK PRODUCTION, 8., 2006, Belo Horizonte. Book Abstracts... Belo Horizonte: WCGALP, 2006. p.251.

PELICIONI, L.C.; QUEIRÓZ, S.A. Efeito da linhagem citoplasmática sobre a produção de leite em bovinos da raça Caracu. Rev. Bras. Zootec., v.30, p.109-114, 2001.

RORATO, P.R.N.; KEOWN, J.F.; VAN VLECK, L.D. Variance caused by citoplasmic line and sire by herd interaction effects for milk yield considering estimation bias. J. Dairy Sci., v.82, p.1574-1580, 1999.

SCHUTZ, M.M.; FREEMAN, A.E.; BEITZ, D.C. et al. The importance of maternal lineage on milk yield traits of dairy cattle. J. Dairy Sci., v.75, p.1331-1341, 1992.

SCHUTZ, M.M.; FREEMAN, A.E.; LINDERG, G.L. et. al. Effects of maternal lineages grouped by mitocondrial genotypes on milk yield and composition. J. Dairy Sci., v.76, p.621-629, 1993. 